\title{
Oily Water Treatment by Ceramic Membrane: Modeling and Simulation
}

\author{
Adriana Barbosa da Costa Pereira1, Hortência Luma Fernandes Magalhães', \\ Leonardo Pereira de Lucena Silva², Cristiane Arcoverde Passos ${ }^{3}$, Ricardo Soares Gomez ${ }^{4}$, \\ Balbina Raquel de Brito Correia ${ }^{4}$, Severino Rodrigues de Farias Neto', \\ Antonio Gilson Barbosa de Lima ${ }^{4}$
}

\footnotetext{
${ }^{1}$ Department of Chemical Engineering, Federal University of Campina Grande, Campina Grande, Brazil ${ }^{2}$ Department of Industry, Federal Institute of Paraiba, Cajazeiras, Brazil ${ }^{3}$ Department of Chemical Engineering, Federal University of Paraná, Curitiba, Brazil ${ }^{4}$ Department of Mechanical Engineering, Federal University of Campina Grande, Campina Grande, Brazil Email: adrianabarbosaabc@yahoo.com.br, hortencia.luma@gmail.com, lucena.leonardo@ifpb.edu.br, cris09arcoverde@gmail.com,ricardosoaresgomez@gmail.com, balbinacorreia@hotmail.com, severino.rodrigues@ufcg.edu.br, antonio.gilson@ufcg.edu.br
}

How to cite this paper: Costa Pereira, A.B., Magalhães, H.L.F., Silva, L.P.L., Passos, C.A., Gomez, R.S., Correia, B.R.B., Farias Neto, S.R. and Lima, A.G.B. (2021) Oily Water Treatment by Ceramic Membrane: Modeling and Simulation. Open Journal of Fluid Dynamics, 11, 1-19. https://doi.org/10.4236/ojfd.2021.111001

Received: November 23, 2020

Accepted: January 11, 2021

Published: January 14, 2021

Copyright $\odot 2021$ by author(s) and Scientific Research Publishing Inc. This work is licensed under the Creative Commons Attribution International License (CC BY 4.0).

http://creativecommons.org/licenses/by/4.0/ (c) (i) Open Access

\begin{abstract}
The separation process of oily water using membranes has attracted the attention of researchers and engineers. The greater problem in the use of membrane separation process is the reduction in permeate flux due to clogged pores by oil deposition inside the membrane or by the effect of the concentration polarization. For this purpose, a theoretical study of a water/oil separation module was performed. This device consists of a tubular ceramic membrane provided with a rectangular inlet section. Numerical simulations were performed using Ansys CFX software to solve the mass and momentum conservation equations in the fluid and porous domains. Here was adopted the RNG $k$ - $\varepsilon$ turbulence model. The effect of the membrane porosity and the inlet velocity of the fluid mixture on the two-phase flow behavior inside the separation module were evaluated. Results of the volumetric fraction, velocity and pressure fields of the oil and water phases are presented and analyzed. The results indicate a higher oil concentration within the membrane for the cases of higher porosity, and that the inlet fluid mixture velocity does not substantially affect the velocity profile within the separation module. It is found that the maximum separation efficiency of the module was obtained with feed velocity of $40 \mathrm{~m} / \mathrm{s}$ and membrane porosity of 0.44 .
\end{abstract}

\section{Keywords}

Ceramic Membranes, Separation Process, Computational Fluid Dynamics, CFX 


\section{Introduction}

The effects of technological advancement have provided countless socio-economic benefits. However, the misuse of such technology and the disregard for its imminent risks might lead to environmental degradation. Several cases of water contamination as well as the reduction in the volume of drinking water have been reported. The most reasonable conclusions point to the need for wastewater treatments, whether residential or industrial, in order to minimize the environmental damage caused by polluted effluents, such as oily water.

Along with the standard oil production process, there is a simultaneous production of oil, gas, sand, and water, consequently requiring adequate separation systems. According to Moraes et al. [1], the water resulting from petroleum production is an undesirable by-product, which is always presented in crude oil extraction.

The oil concentration in the produced water can vary from relatively low values, ranging from 50 to $600 \mathrm{mg} / \mathrm{L}$ [2] [3] [4], to higher values, above $1000 \mathrm{mg} / \mathrm{L}$ [2] [5]. For this reason, and to obey environmental legislation, the contaminated water treatment is necessary for subsequent reuse or disposal.

There are some separation processes commonly used by the oil industry for the treatment of oily water, such as: flotation equipment, clarifiers, and absorbers, settling tanks, hydro-cyclones and centrifuges. However, these devices are restricted to separate particles with a diameter of $10 \mu \mathrm{m}$ [6] [7]. An alternative that has been studied is the use of membrane-based separation processes that is well indicated for particles with a diameter smaller than $10 \mu \mathrm{m}$. This is a clean and easy handling technique and at a low cost. Thus, the use of membranes is economically competitive when compared to other separation processes.

Membranes act as selective barriers to particle transportation. They perform the separation into two phases and control the flow of particles in each of them. The membrane filtration results in permeate flux (liquid driven through the membrane) and concentrated fluid (retained liquid containing the feed contaminants). According to Thomas et al. [8], membrane separation processes usually occur without phase change, and with energy saving. Their properties may be established according to the desirable application.

The flow setting is an important feature in membrane-based filtration processes and it may occur in two different ways: Cross-flow filtration (also known as tangential flow filtration) and dead-end filtration (the conventional method for perpendicular flow). The feed mixture flux in the dead-end filtration method is frontally forced against the membrane, which causes the retained particles to rapidly coagulate on the membrane surface, gathering solute (suspended solids). This phenomenon is called Concentration Polarization and it is responsible to reduce the separation performance. In the cross-flow filtration method, the tangential flux reduces the solute accumulation due to the particle movements. For this reason, tangential flow operations are chosen for industrial applications which deal mainly with higher concentrations of suspended solids [9] 


\section{[10] [11].}

Depending on the nature and type of solutes and presence of suspended particles, membranes with different sizes and pores distribution can be classified as MicroFiltration (MF), UltraFiltration (UF), NanoFiltration (NF) and Reverse Osmosis (RO) [12]. We state that microfiltration membranes are used in separation where particles with 0.1 to $10 \mu \mathrm{m}$ diameter are present, ultrafiltration membranes for particles with diameter of 0.005 to $0.05 \mu \mathrm{m}$, nanofiltration for 0.0005 to $0.005 \mu \mathrm{m}$ particle diameter, and finally reverse osmosis which is applied when particles with 0.0001 to $0.001 \mu \mathrm{m}$ diameter are present in the fluid mixture.

The modeling and simulation of problems involving oily water separation by membranes is complex, requiring a deep theoretical basis. The separation process occurs over time thus, some changes in the characteristics and properties of the membrane can be observed. Besides, solute accumulation at interface membrane/solution is inevitable. Because of the importance, several studies involving the membrane separation process with computer codes' aid based on CFD tools (Computational Fluid Dynamics) have been conducted, for example, Porciúncula [9], Vieira et al. [13], Souza [14], Cunha [15], Cunha et al. [16], Cunha et al. [17], Magalhães et al. [18], Souza et al. [19], Magalhães et al. [20], Oliveira [21] and Magalhães et al. [22].

As a complement to these studies, this work aims to simulate the oily water treatment by a new configuration of the ceramic membrane using CFD tools. Based on the earlier discussions, the present work is motivated by the growing importance of separation processes using membranes, especially that using ceramic membranes, and by the fact that most of the experimental and numerical works reported in the literature have used polymeric membranes. The contribution of this research is directed to answer some questions involved in effluent treatment by ceramic membranes not yet well understand, such as membrane geometry, 3D fluid flow behavior and oil concentration inside the membrane which strongly affect the separation performance.

\section{Methodology}

\subsection{Problem Description and Mesh Generation}

The study domain basically is a separation module consisting of a tube with a porous wall (ceramic membrane), as shown in Figure 1(c). The water-oil mixture feeds the module through a duct of rectangular section positioned perpendicularly and tangentially to the membrane, as illustrated in Figure 1. For simulations, the physical domain was converted in a structured mesh, consisting of 50580 hexahedral elements (Figure 2). This procedure was done using the ICEM CFD software and the blocking technique.

Different simulations were performed to identify the non-dependence of the results with the mesh and number of interactions $(5000,8000,11,000,14,000$, and 17,000), directly related to the computational time used in solving the 


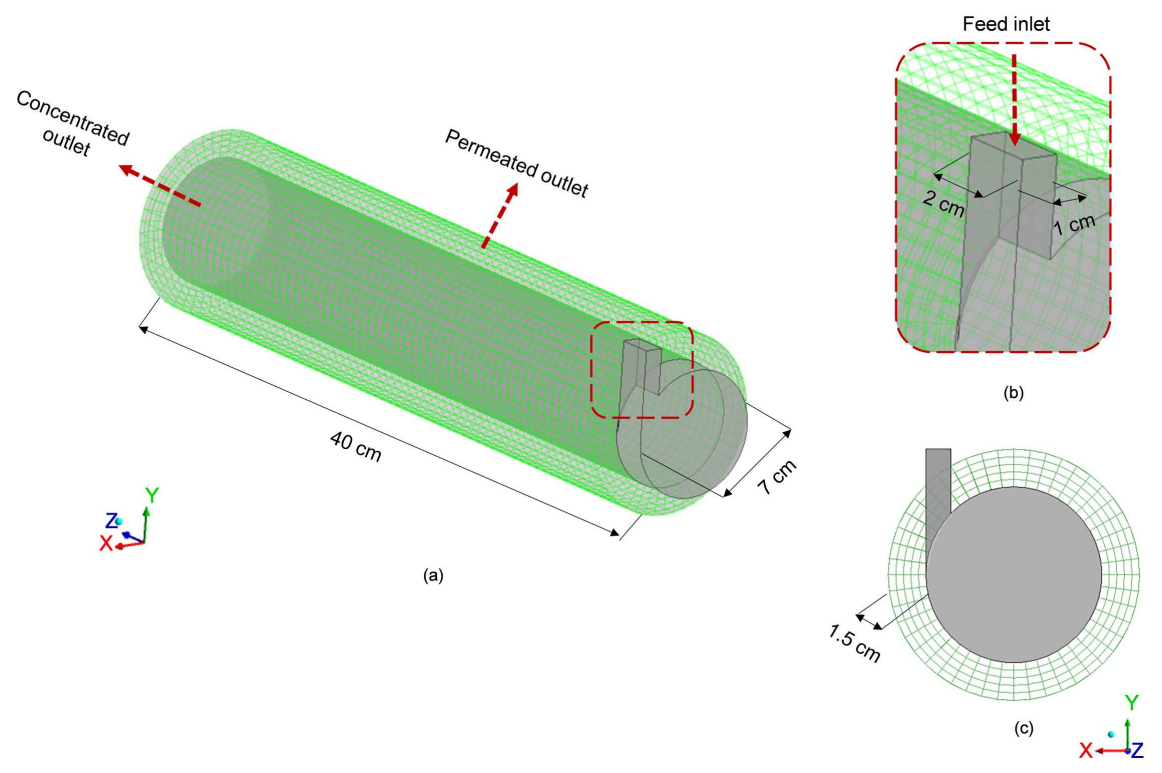

Figure 1. Illustration of the ceramic membrane with its main dimensions. (a) Geometry, (b) inlet and (c) front view of module inlet.

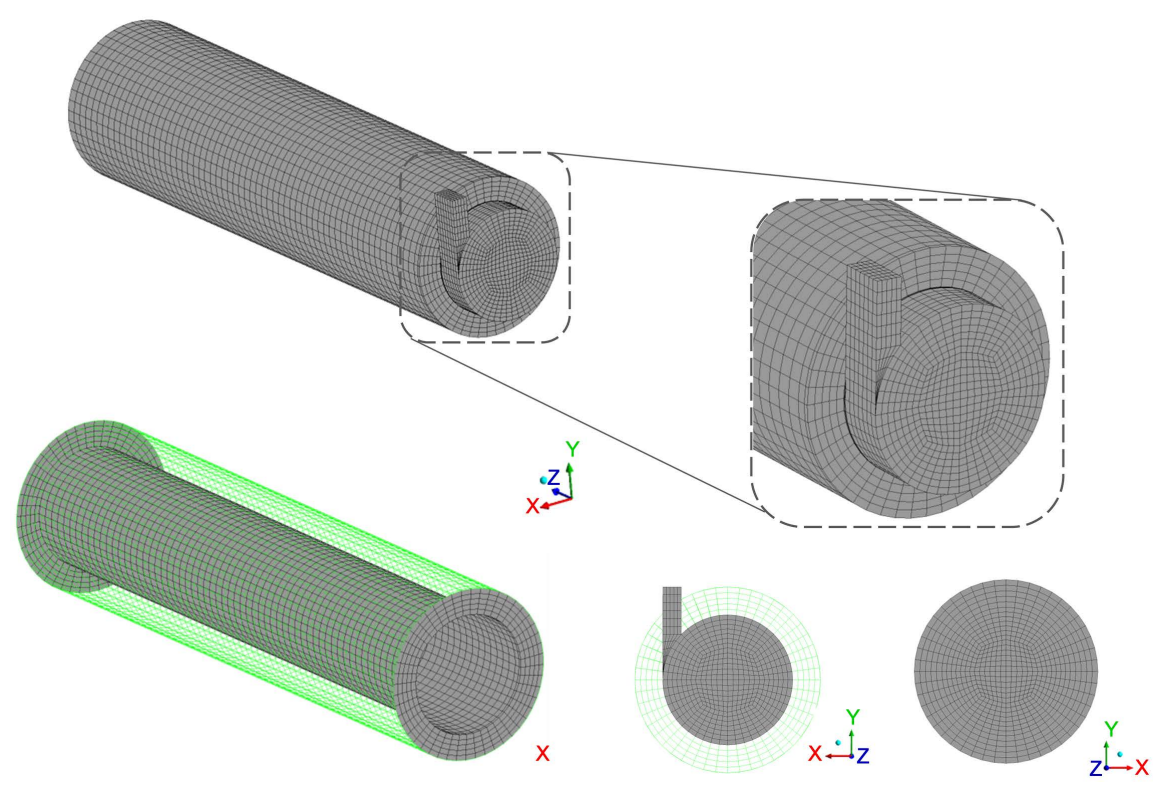

Figure 2. Details of the hexahedral mesh used in the simulation.

simulations for the studied separation phenomenon. Then, three membrane porosities were assumed, $(0.35,0.40$ and 0.44$)$ and three input velocities of the mixture, $\left(U_{\text {feed }}=35,40\right.$ and $\left.45 \mathrm{~m} / \mathrm{s}\right)$ in the separation module. All simulations of the fluid separation process were performed using the Ansys CFX software.

\subsection{Advanced Mathematical Modeling}

The mathematical model defined to describe an oil/water flow separating process is based on the generalized equations mass and momentum conservation of the RNG k- $\varepsilon$ model turbulence. The following considerations were adopted: 
1) Newtonian and incompressible fluid;

2) Steady-state flow regime;

3) Isothermal flow;

4) Constant physical and chemical properties of the fluids;

5) The chemical reaction, mass transfer between the phases, and mass source are disregarded;

6) The interfacial drag force was considered;

7) The oil droplets are spherical and non-deformable.

The mathematical model does not predict the phenomenon of retention of molecules or particles in the porous medium, however, it considers the difficulty or resistance to the passage of the phases (oil and water) into porous media. Based on the considerations cited earlier and using an Eulerian-Eulerian approach, the following equations are given:

Mass conservation equation

\section{- For the fluid phases}

$$
\nabla \cdot\left(f_{\alpha} \rho_{\alpha} \vec{U}_{\alpha}\right)=0
$$

where $\alpha$ is the phase (water or oil), $f, \rho$ and $\vec{U}$ represent volumetric fraction, density and velocity vector, respectively.

\section{- For the porous medium (ceramic membrane)}

$$
\nabla \cdot\left(f_{\alpha} \rho_{\alpha} K \vec{U}_{\alpha}\right)=0
$$

where $K=\left(K^{i j}\right)$ is a symmetric second-rank tensor, called the permeability tensor.

Momentum transfer equation

\section{- For the fluid phases}

$$
\begin{aligned}
& \nabla \cdot\left[f_{\alpha}\left(\rho_{\alpha} \vec{U}_{\alpha} \otimes \vec{U}_{\alpha}\right)\right] \\
& =-f_{\alpha} \nabla p_{\alpha}+\nabla \cdot\left\{f_{\alpha} \mu_{e}\left[\nabla \vec{U}_{\alpha}+\left(\nabla \vec{U}_{\alpha}\right)^{\mathrm{T}}\right]\right\}+\vec{S}_{M_{\alpha}}+\vec{M}_{\alpha}
\end{aligned}
$$

where $p$ is the pressure, $\vec{S}_{M_{\alpha}}$ it is the term of external forces acting on the system per unit volume, $\vec{M}_{\alpha}$ describes the overall strength per unit volume on the a phase due to interaction with the $\beta$ phase. This parameter is given as follows:

$$
M_{\alpha}=M_{\alpha \beta}^{D}=\frac{3 C_{D}}{4 d_{p}} f_{\beta} \rho_{\alpha}\left|\boldsymbol{U}_{\alpha}-\boldsymbol{U}_{\beta}\right| \cdot\left(\boldsymbol{U}_{\alpha}-\boldsymbol{U}_{\beta}\right)
$$

where $d_{p}$ is the particle diameter and $C_{D}$ is drag coefficient, which was assumed to be equal to 0.44 .

\section{- For the porous media}

The following equation defines the momentum conservation for the porous media:

$$
\nabla \cdot\left[f_{\alpha} \rho_{\alpha}(\boldsymbol{K} \cdot \vec{U}) \otimes \vec{U}\right]=-\nabla p+\nabla \cdot\left\{f_{\alpha} \mu_{e} \boldsymbol{K} \cdot\left[\nabla U+\left(\nabla \vec{U}_{i}\right)^{\mathrm{T}}\right]\right\}+\vec{S}_{i}^{M}
$$

where $\mu_{e}$ is the effective viscosity defined by the Equations (6) and $\vec{S}_{i}^{M}$ is the 
linear momentum source term:

$$
\mu_{e}=\mu_{\alpha}+\mu_{T}
$$

In equation $\mu_{\alpha}$ is the dynamic viscosity and $\mu_{T}$ represents the turbulent viscosity given by Equation (9).

Turbulence model

In this research, it was used the RNG $k$ - $\varepsilon$ turbulence model. In this model, the transport equations for estimating the variables, $k$, turbulent kinetic energy (dimensions $\mathrm{L}^{2} \cdot \mathrm{T}^{-2}$ ) and, $\varepsilon$, turbulent dissipation rate (dimensions $\mathrm{L}^{2} \cdot \mathrm{T}^{-3}$ ) are given as follows:

$$
\begin{gathered}
\frac{\partial(\rho k)}{\partial t}+\nabla\left(\rho U_{j} k\right)=\nabla \cdot\left[\left(\mu+\frac{\mu_{t}}{\sigma_{k R N G}}\right) \nabla \kappa\right]+P_{k}-\rho \varepsilon \\
\frac{\partial(\rho \varepsilon)}{\partial t}+\nabla \cdot\left(\rho U_{j} \varepsilon\right)=\nabla \cdot\left[\left(\mu+\frac{\mu_{t}}{\sigma_{\varepsilon R N G}}\right) \nabla \varepsilon\right]+\frac{\varepsilon}{k}\left(C_{\varepsilon 1 R N G} P_{k}-C_{\varepsilon 2 R N G} \rho \varepsilon\right)
\end{gathered}
$$

where $\mu$ is the dynamic viscosity and $\mu_{t}$ is the eddy viscosity, which is given by:

$$
\mu_{t}=C_{\mu} \rho \frac{k^{2}}{\varepsilon}
$$

where $C_{\mu}$ is an empirical constant. In the Equations (7), (8) and (9),

$$
\begin{gathered}
C_{\mu}=\sigma_{\varepsilon R N G}=\sigma_{\kappa R N G}=0.7179 \\
C_{\varepsilon 2 R N G}=1.68 \\
C_{\varepsilon 1 R N G}=1.42-\frac{\eta\left(1-\frac{\eta}{4.38}\right)}{1+\eta^{3} \beta_{R N G}}
\end{gathered}
$$

where $\eta$ is defined as follows:

$$
\eta=\sqrt{\frac{P_{\kappa}}{\rho \varepsilon C_{\mu R N G}}}
$$

where $C_{\mu R N G}=0.085$ is the constant that appears in the RNG $\kappa-\mathcal{E}$ turbulence model (ANSYS CFX 12.1), $P_{\kappa}$ is the production of turbulence due to the viscosity and shear forces, defined as follows:

$$
P_{\kappa}=\mu_{t} \nabla U \cdot(\nabla U+\nabla U)^{T}+P_{\kappa B}
$$

where the term $P_{\kappa B}$ is the buoyant production, defined in Equation (15).

$$
P_{k B}=-\frac{\mu_{t}}{\rho \sigma_{\mu}} g \cdot \nabla \rho
$$

where $g$ is gravity acceleration and $P_{k B}$ is Prandtl's number turbulent.

\subsection{Boundary Conditions}

For a complete mathematical modeling, different boundary conditions were previously defined, which can be observed in Table 1 . 
Table 1. Boundary conditions used in the simulation.

\begin{tabular}{ccc}
\hline Location & Type (Ansys CFX) & Boundary conditions \\
\hline Feeding & Inlet & $f_{\text {oil }}=0.05$ \\
& & $U_{x}=U_{z}=0$ \\
& $U_{y}=U_{\text {feed }}$ \\
\hline Permeated outlet & $\frac{\partial U_{i}}{\partial x_{i}}=0$ \\
& Outlet & $P=99,000 \mathrm{~Pa}$ \\
\hline Wall (non-slip condition) & Wall & $U_{x}=U_{y}=U_{z}=0$ \\
\hline Concentrated outlet & Outlet & $\frac{\partial U_{i}}{\partial x_{i}}=0$
\end{tabular}

\subsection{Materials Parameters and Simulated Cases}

The properties of fluid phases (water and oil) and porous media used in the simulations are shown in Table 2, and the studied cases are reported in Table 3.

\section{Results and Discussions}

\subsection{Numerical Analysis Procedure}

On the simulation study is very important to perform mesh refinement and number of iterations studies, in order to obtain confiability and precision in the obtained results. The aim is to obtain results with lower computational cost and great precision. As a first step, a numerical analysis to determine the effect of the number of iterations in the obtained results was performed. In the study, five variations on the number of iterations $(5000,8000,11,000,14,000$ and 17,000 iterations) were established and, thus, the direct relation between the simulation runs and generation of results was verified.

The set of studies was carried out the principle of superposition of the water velocity profile curves near the tangential entrance along the membrane, as defined in Figure 3.

In Figure 3, it is possible to verify that regardless of the iteration number proposed in the simulation, there is a similar response of the variable in the process, especially when observing the profiles obtained with 5000 and 8000 iterations. Thus, 5000 iterations were used in the present study, given that satisfactory results were obtained for the case studied $(\theta=0.44$, Table 3$)$ with lower computational cost.

The velocity profiles shown in Figure $3(\mathrm{~b})$ were obtained in the highlighted line in Figure 3(a). The choice of this location is due to the strong influence that the tangential inlet has on the flow behavior inside the membrane.

\subsection{Hydrodynamic Analysis}

\subsubsection{The Effect of the Membrane Porosity}

Figure 4 shows the oil volume fraction distribution on the YZ and ZX longitudinal 


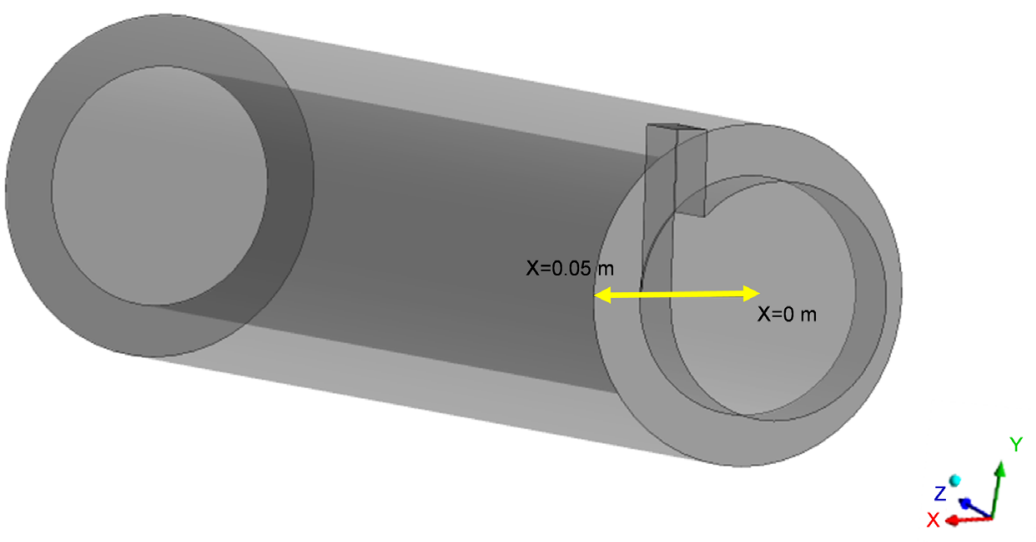

(a)

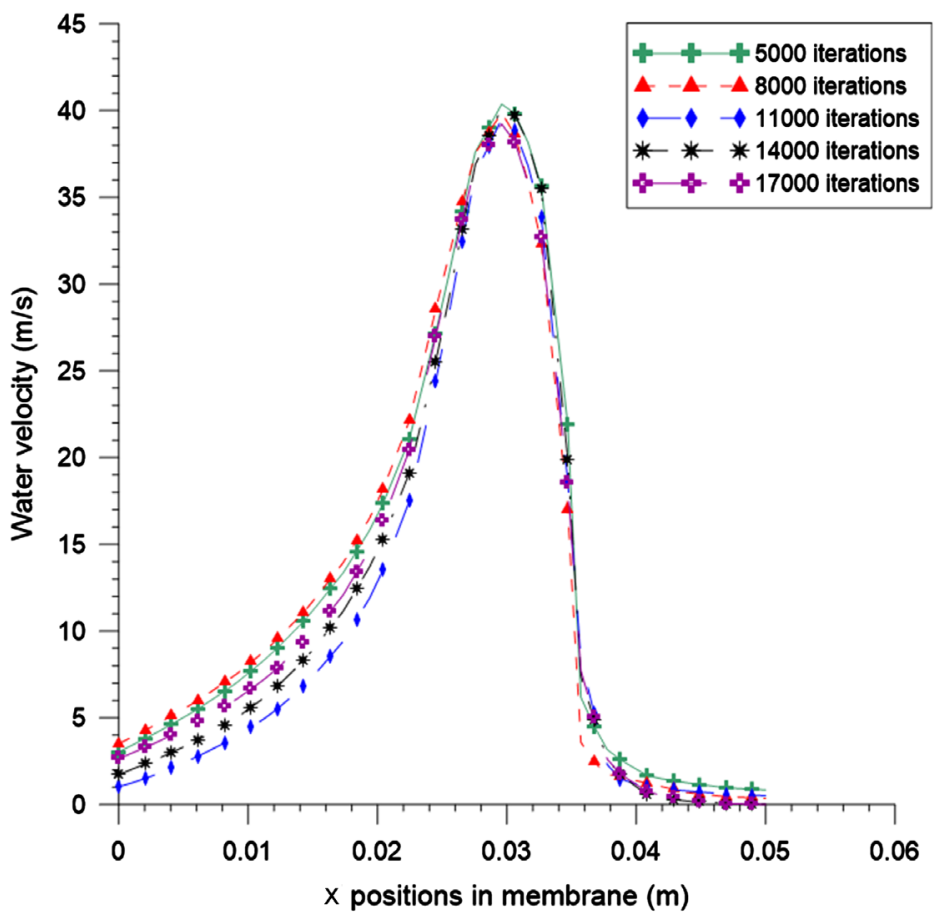

(b)

Figure 3. Velocity profiles of water inside the membrane at different positions along the yellow line on the (a).

Table 2. Physical and chemical parameters of the membrane and fluid.

\begin{tabular}{ccc}
\hline Material & Property & Value \\
\hline \multirow{2}{*}{ Water } & Density $\left(\mathrm{kg} / \mathrm{m}^{3}\right)$ & 997 \\
& Viscosity $(\mathrm{Pa} / \mathrm{s})$ & $8.89 \times 10^{-4}$ \\
\hline \multirow{2}{*}{ Oil } & Density $\left(\mathrm{kg} / \mathrm{m}^{3}\right)$ & 868.7 \\
& Viscosity $(\mathrm{Pa} / \mathrm{s})$ & $7.6 \times 10^{-2}$ \\
\hline \multirow{2}{*}{ Ceramic membrane } & Porosity & $\theta$ (Available in Table 3) \\
& Permeability $\left(\mathrm{m}^{2}\right)$ & $2.29 \times 10^{-10}$ \\
\hline
\end{tabular}




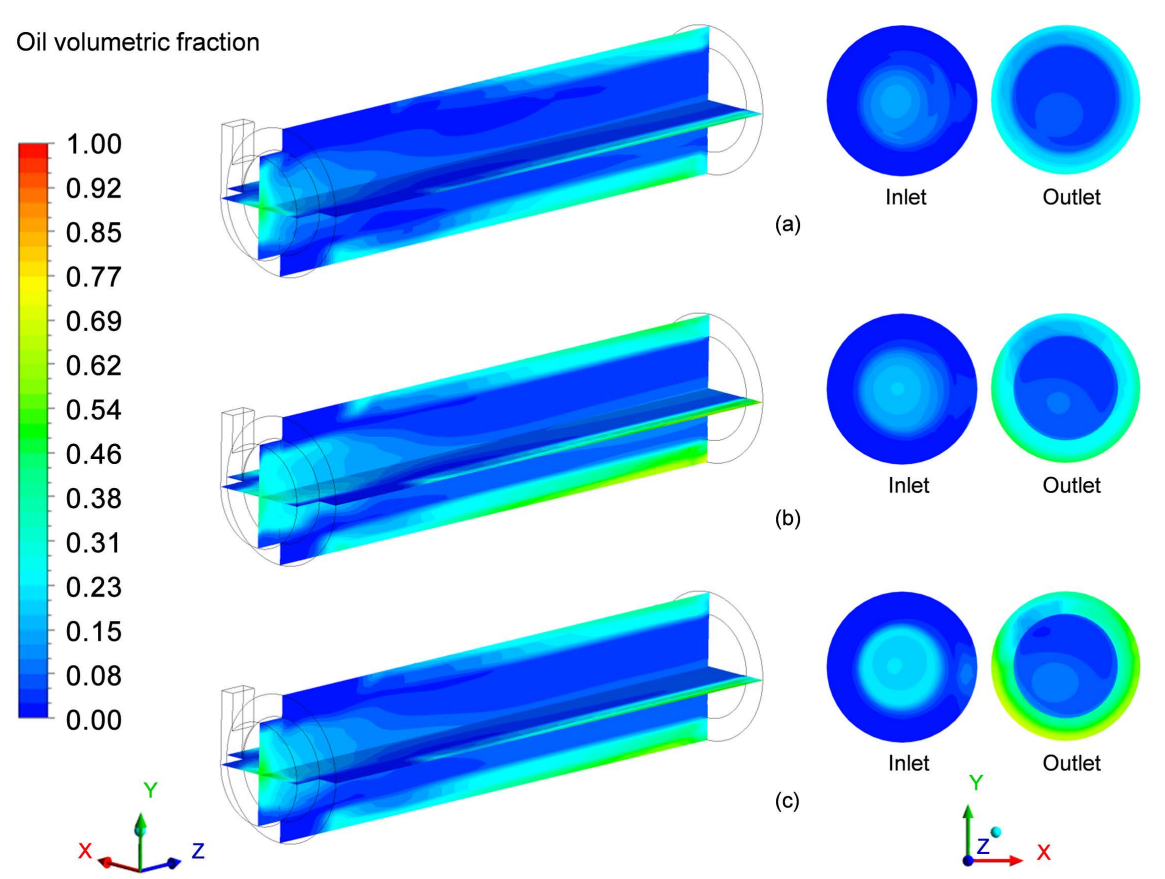

Figure 4. Oil volume fraction distribution in the $\mathrm{YZ}$ and $\mathrm{ZX}$ longitudinal planes and $\mathrm{XY}$ transversal planes (inlet and outlet) of the membrane, for different porosities (a) 0.35 ; (b) 0.40 and (c) 0.44 .

Table 3. The studied cases in this research.

\begin{tabular}{ccc}
\hline Case & Feed velocity $\left(\mathrm{U}_{\text {feed }}\right)(\mathrm{m} / \mathrm{s})$ & Porosity $(\theta)(-)$ \\
\hline 1 & 40 & 0.35 \\
2 & 40 & 0.40 \\
3 & 40 & 0.44 \\
4 & 35 & 0.35 \\
5 & 45 & 0.35 \\
\hline
\end{tabular}

planes that pass through the center of the membrane and on the transverse planes at the inlet and outlet of the separation module for different porosity (Cases $\theta=0.35, \theta=0.40$ and $\theta=0.44$ ). By analyzing Figure 4 , it is noted that the regions with higher oil concentration in the module are located in the edges of the plans, which correspond to the area where the ceramic membrane is located. This phenomenon indicates that there is oil saturation in those regions, which leads to possible oil retention within the membrane. For the case where the membrane has 0.35 porosity, lower oil volume fractions are found on the edge regions as compared with the same membranes with porosity of 0.40 and 0.44 . This result is interesting because it indicates a greater selectivity for oil passage through the porous medium and lower oil concentration polarization layer thickness on the membrane surface.

The behavior of the oil fraction concentration observed for the module's entry planes presented in Figure 4 showed similarity for the three membrane porosi- 
ties. In the module's exit planes, shown in the aforementioned figure, different behavior is found, with lower oil volume fraction concentration for the membrane with minor porosity $(\theta=0.35)$.

Figure 5 illustrates the oil volume fraction distribution at the different $\mathrm{XY}$ transversal planes along the device. By analyzing Figure 5, it can be seen that as the flow occurs, there is a tendency to increase the oil volume fraction in the membrane and a more significant accumulation and/or passage of these particles at the ends of the membrane. This flow behavior occurs radially from the center of the device to the outer wall of the membrane.

The oil behavior observed in Figure 5 can be explained by two factors: 1) the action of gravity, due to the horizontal positioning of the equipment, which has a direct influence on the oil particles deposition in the outer wall of the membrane, especially for the studied case with higher membrane porosity, and 2) the appearance of recirculation zones close to the tangential entrance, providing a bigger carrying of oil particles and, consequently, lower oil accumulation in this region.

Figure 6 presents the pressure fields for different positions in the separation module for different porosities 0.35 (a), 0.40 (b) and 0.44 (c) (filtrate interface

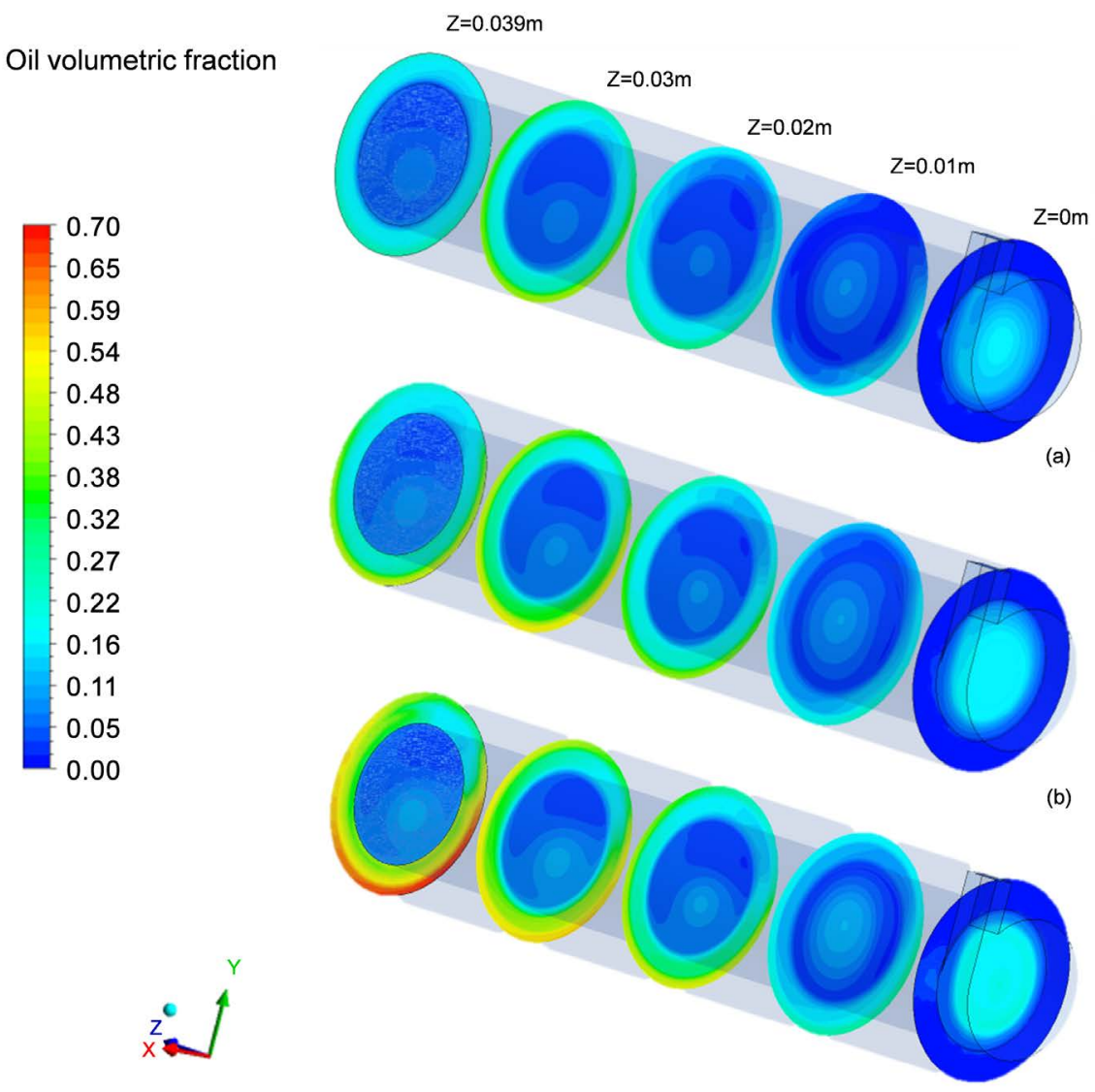

(c)

Figure 5. Oil volume fraction distribution at $\mathrm{XY}$ transversal planes along the device for different membrane porosities: (a) 0.35 ; (b) 0.40 and (c) 0.44 . 

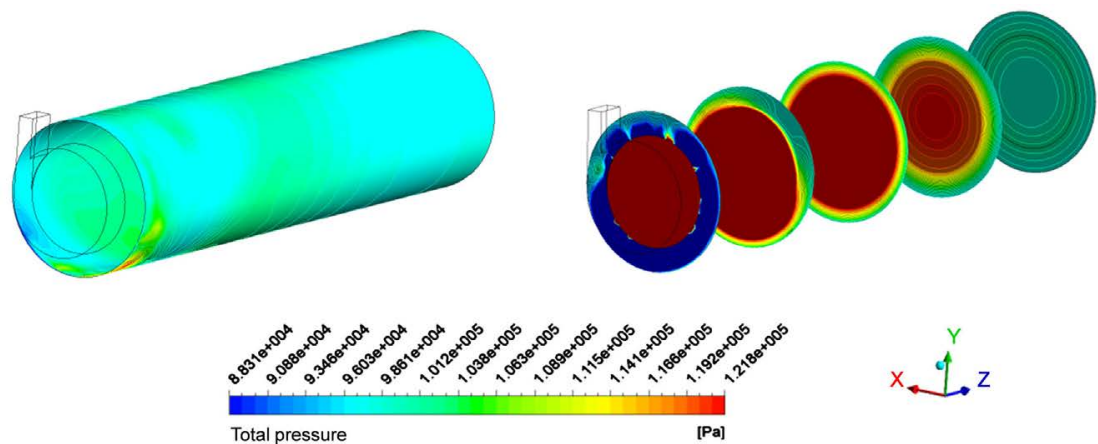

(a)
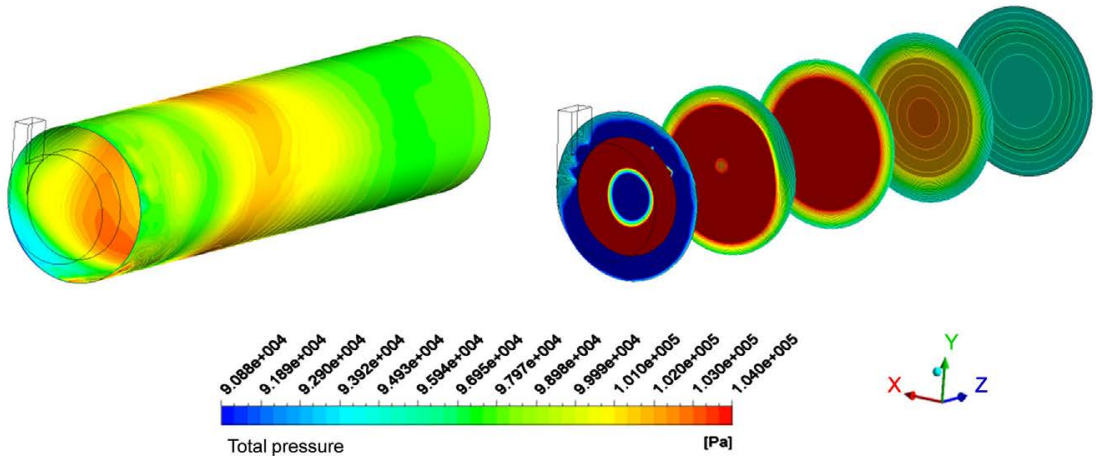

(b)
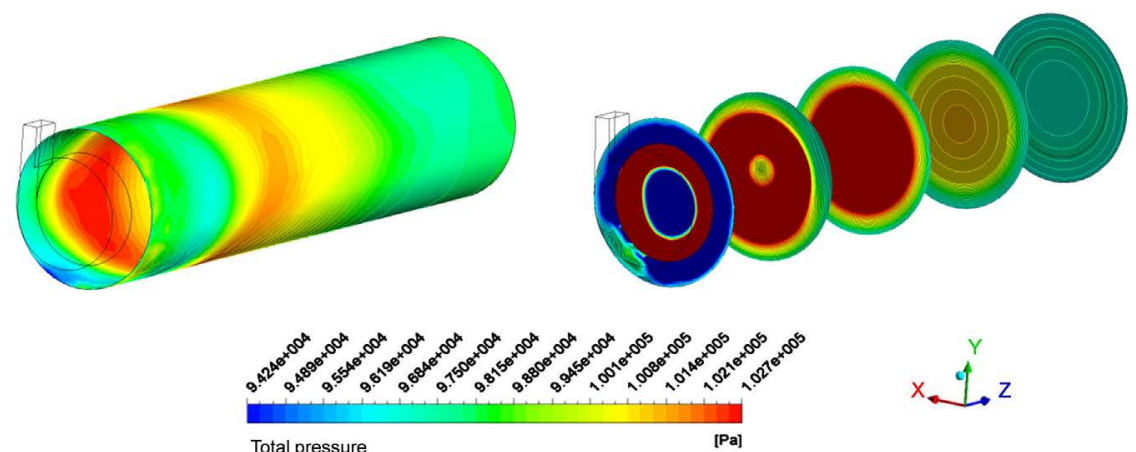

(c)

Figure 6. Pressure distribution in the XY transverse planes and in the surface membrane, along the $\mathrm{z}$-axis for different membrane porosities: (a) 0.35 ; (b) 0.40 and (c) 0.44 .

and $\mathrm{XY}$ longitudinal planes). By analyzing the $\mathrm{XY}$ transversal plane, it is observed a similarity in the results for the three cases of membrane porosity in terms of the pressure distribution except for the plane closest to the tangential inlet (XY plane at $\mathrm{z}=0.0 \mathrm{~m}$ ), where turbulence is more pronounced. This existing eddy contributes to the presence of greater pressure in the regions close to the inner wall of the membrane, and sometimes the pressure drops in the innermost regions of the module.

Despite different values scales, pressure fields at the membrane surface and transversal planes, illustrated in Figure 6, it had similar results in their maximum and minimum values. The maximum value $121.8 \mathrm{kPa}$ was found at the re- 
gion close to the feeding of the membrane module (Figure 6(a)). For the membranes with porosities of 0.40 and 0.44 , the lower pressure values were found in regions close to the entrance of the device as well as in regions distributed throughout the module, which have presented higher accumulation of oil inside the membrane.

\subsubsection{The Effect of Feed Fluid Mixture Velocity}

Figure 7 shows the velocity profiles as a function of radial position in three longitudinal positions. On the $\mathrm{XZ}$ longitudinal plane it was represented the velocity

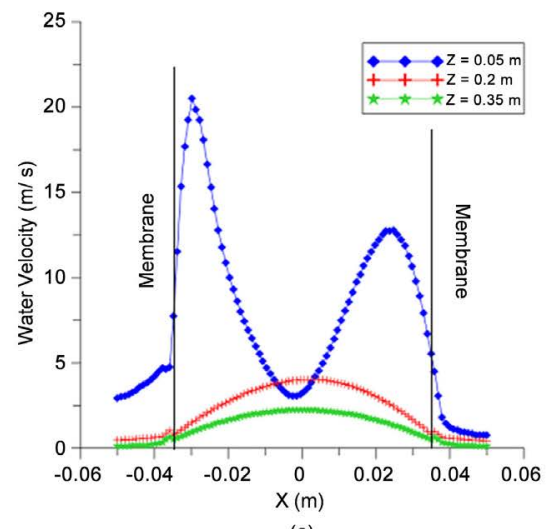

(a)
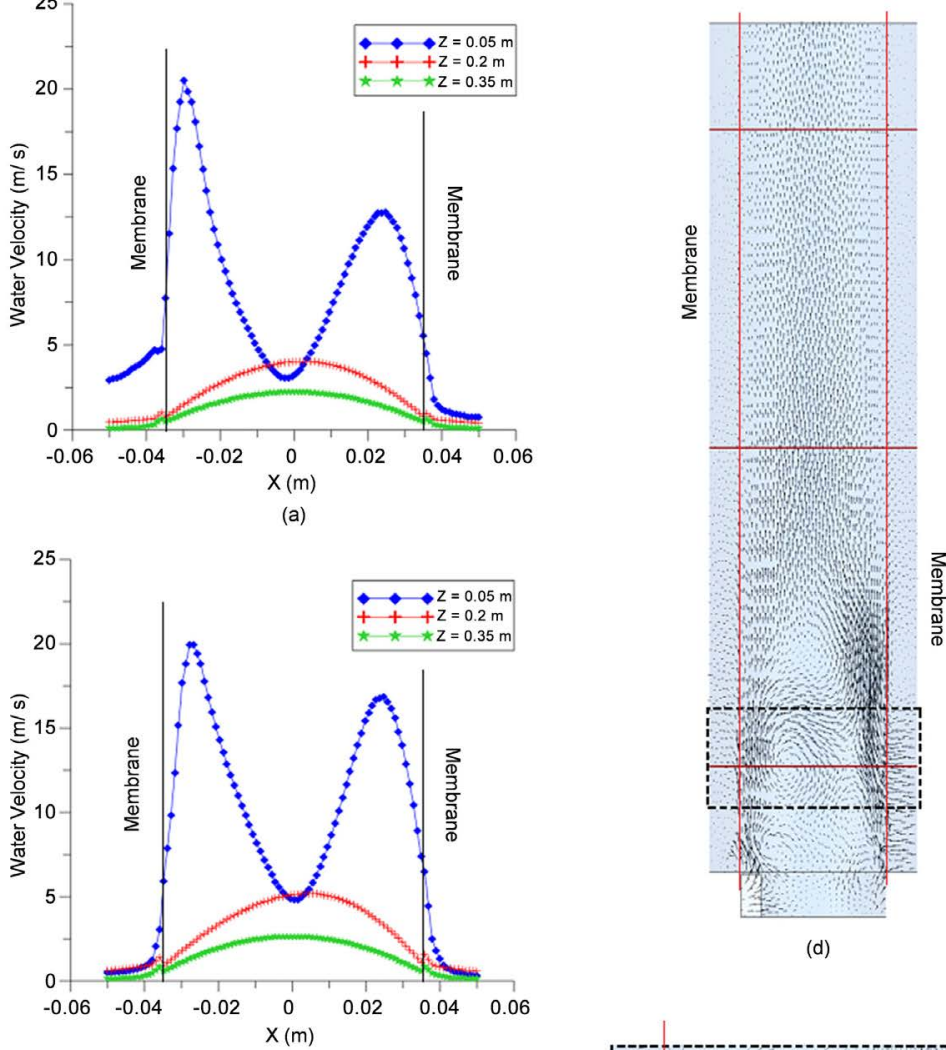

(d)

(b)
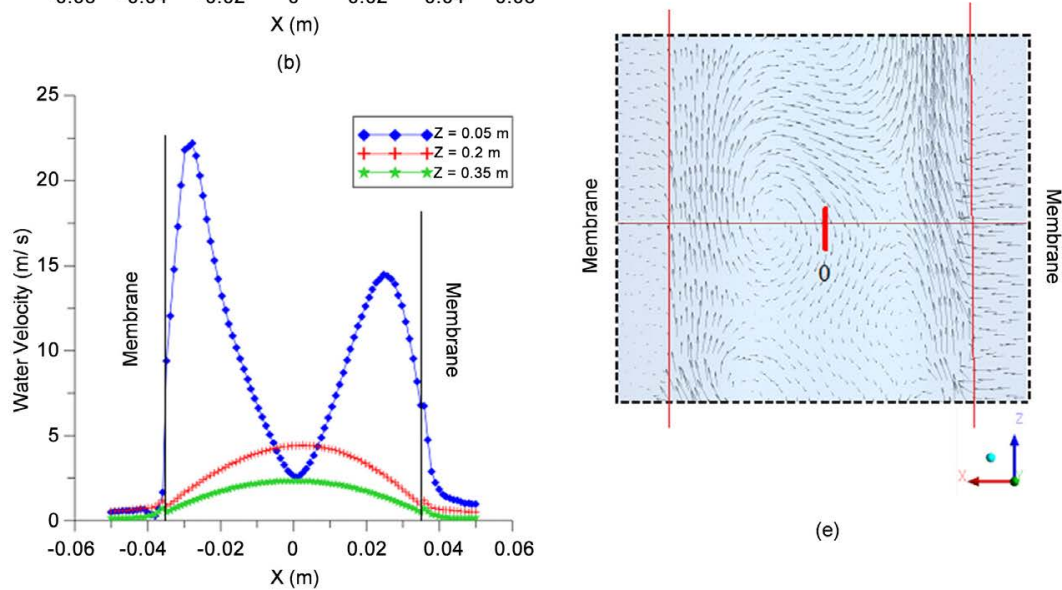

(e)

(c)

Figure 7. Water velocity profiles within the membrane module, along the $\mathrm{x}$-axis $(\mathrm{Y}=0$ m) for feed fluid velocity: (a) $35 \mathrm{~m} / \mathrm{s}$; (b) $40 \mathrm{~m} / \mathrm{s}$ and (c) $45 \mathrm{~m} / \mathrm{s}$. 
vector field for the condition of $35 \mathrm{~m} / \mathrm{s}$ (Figure 7(d) and Figure 7(e)) for the purpose of explaining the fluid flow behavior within the module and assisting in explaining the behavior of the velocity profiles. The velocity profiles were obtained for three different segments in the membrane, represented by lines highlighted in red, one near the tangential inlet, a second located at the center of the length of the membrane, and the last one at the region far from the inlet and near the axial outlet. Upon examining this figure, it is observed similar behavior of the velocity profiles for the feed rates in tangential inlet of 35,40 and $45 \mathrm{~m} / \mathrm{s}$.

The zero value on the abscissa axis shown in the graphs corresponds to the center of the inner pipe. At this point it can be seen the minor velocity values and rising in direction to the membrane surface reaching the "spikes" can be explained by the recirculation zones. For minor distance to the membrane surface velocities values tend to be reduced drastically.

In Figure 7 we can see, clearly, the presence of recirculation areas close to the tangential inlet duct, where the eddy intensity is more significant, that is, where the angular momentum exceeds the axial moment. The decrease in the turbulent intensity can be evidenced in the $\mathrm{z}$ positions, especially in $Z=0.2$ and $0.35 \mathrm{~m}$, indicating that axial moment dominates in these regions. Despite the behavior of the velocity profiles, it can be seen that they are very similar in all fluid mixture feed rates, but with different magnitudes.

The second analysis concerns the pressure profiles for the three analyzed cases of the feed water-oil mixture velocity for the membrane with porosity of $0.35 \mathrm{~m}$. In Figure 8, regardless of the feed fluid velocity, it is possible to observe a similar behavior of the pressure for all analyzed cases, along the module $(Z=0.05,0.2$ and $0.35 \mathrm{~m}$ ), except in $Z=0.05 \mathrm{~m}$, for the region closest to the tangential inlet and feed velocity of $35 \mathrm{~m} / \mathrm{s}$ (Figure 8(a)). Similar behavior was verified to velocity profile (Figure 7).

The region highlighted in Figure 8(b) shows a decreasing pressure profile inside the module, with a direct correlation with that shown in Figure 7(a), a region of increasing water velocity inside the module. Then, higher feeding velocity of the mixture in the module, promoted a lower membrane resistance to the passage of water (filtrate), while a lower feeding velocity $(35 \mathrm{~m} / \mathrm{s}$ ) allowed a return of the filtrate to the module, as can be observed by the velocity vector fields in Figure 7(d) and Figure 7(e), and consequently a miminum of pressure in this region. This phenomenon is observed qualitatively by the swirling zones in the region close to the feed module, that justifies the drop in pressure, or even lower pressure zones in the module.

Figure 9 shows the oil volumetric fraction in the entire module for feed velocity of 35,40 and $45 \mathrm{~m} / \mathrm{s}$. The dotted regions for each case studied refer to the membrane regions observed in Figure 9. In the regions of Figures 9(a)-(c), we can see that the case of lower feed velocity $(35 \mathrm{~m} / \mathrm{s})$ and stretch of the membrane between $\mathrm{X}=-0.05$ and $\mathrm{X}=-0.035 \mathrm{~m}$, presented higher values for volume oil fraction when compared to other studied cases. 


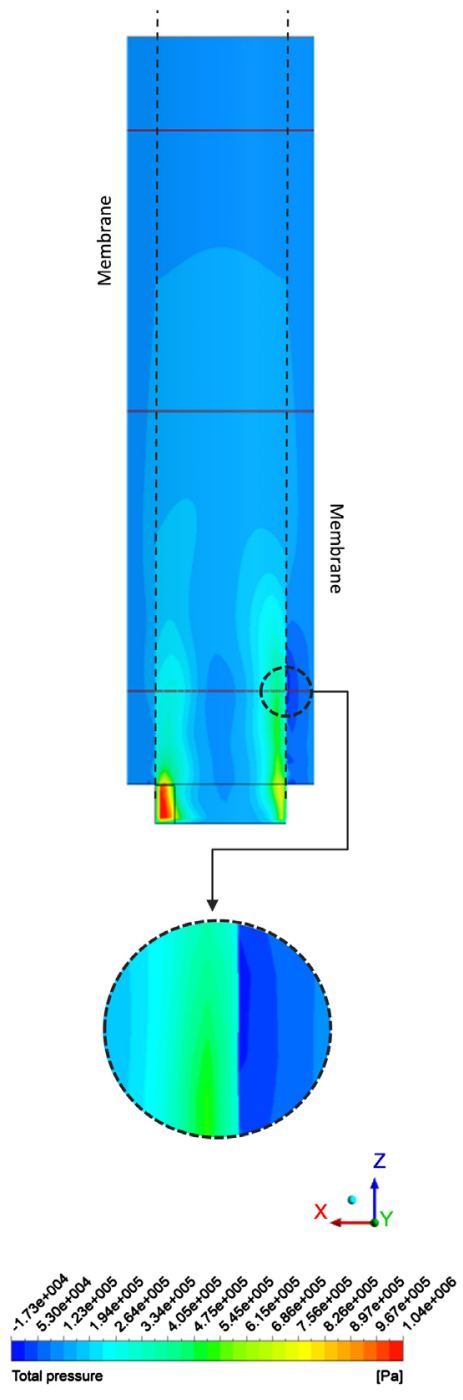

(a)

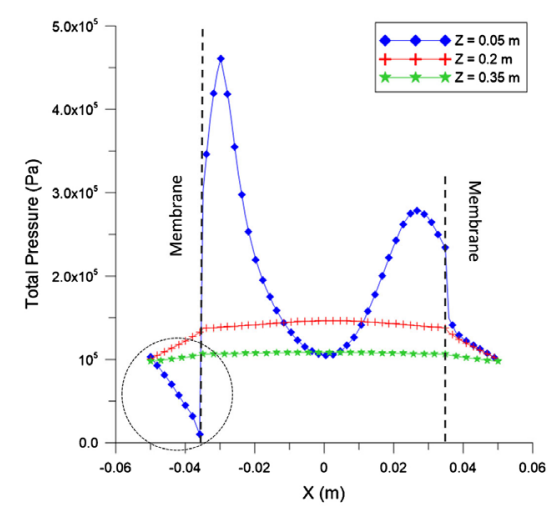

(b)

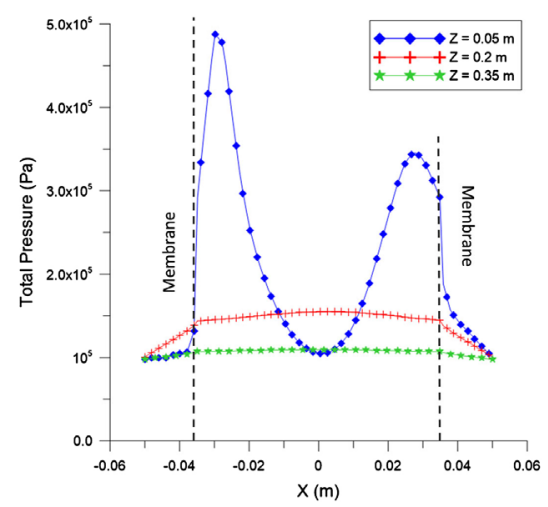

(c)

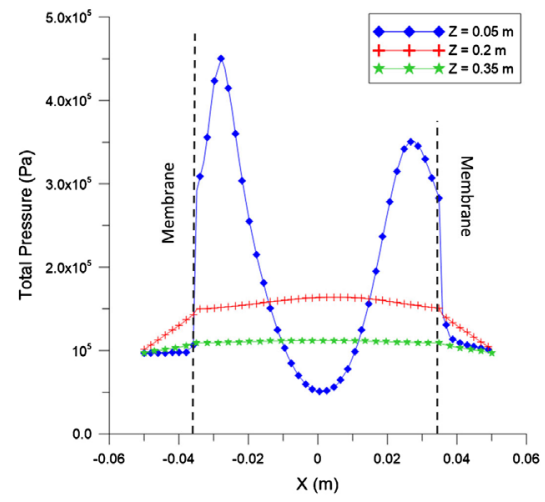

Figure 8. Pressure behaviorinside the membrane moduleat the $\mathrm{Y}=0 \mathrm{~m}$ plane, for feed fluid mixture velocity: (a) $35 \mathrm{~m} / \mathrm{s}$; (b) $35 \mathrm{~m} / \mathrm{s}$; (c) $40 \mathrm{~m} / \mathrm{s}$ and (d) $45 \mathrm{~m} / \mathrm{s}$.

Despite the small difference between the values of oil distribution in the membrane for the three velocity cases, an injection velocity of $35 \mathrm{~m} / \mathrm{s}$, Figure 9(a), caused a greater accumulation of oil in the external interface of the membrane or even filtered, as expected, considering that higher injection velocities can cause a greater fraction of oil to pass through the membrane, that is, less resistance of the membrane to the oil passage.

It is interesting to note that the distribution of the volume oil fraction throughout the module showed a similar behavior regardless of the feed velocity of the fluid mixture, as observed in Figure 10. In this figure we can see that 


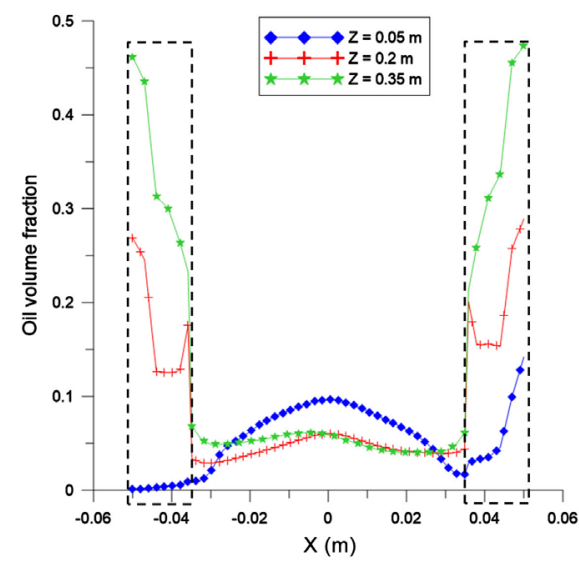

(a)

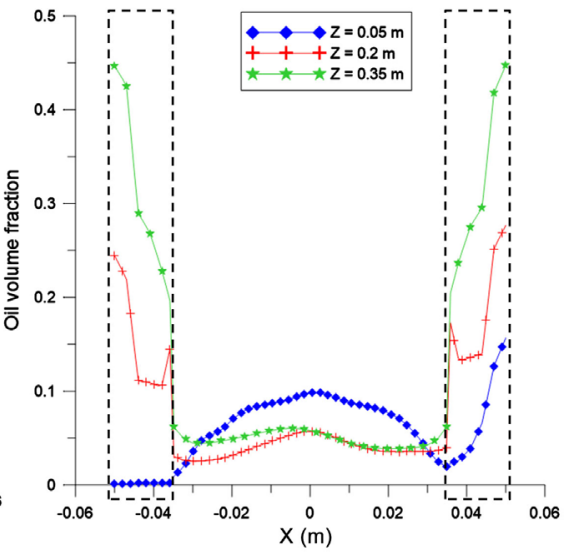

(b)

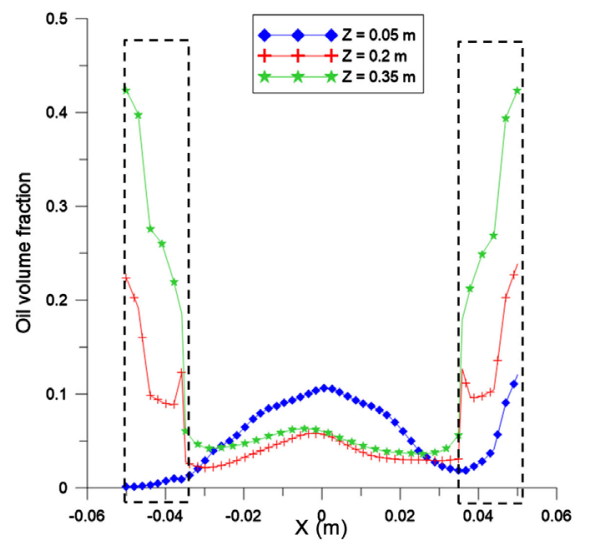

(c)

Figure 9. Oil volume fraction profiles in the membrane, along the $\mathrm{x}$-axis $(\mathrm{Y}=0 \mathrm{~m}$ ) for feed velocity: (a) $35 \mathrm{~m} / \mathrm{s}$; (b) $40 \mathrm{~m} / \mathrm{s}$ and (c) $45 \mathrm{~m} / \mathrm{s}$.

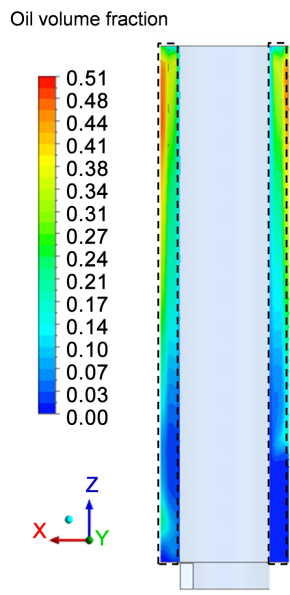

(a)

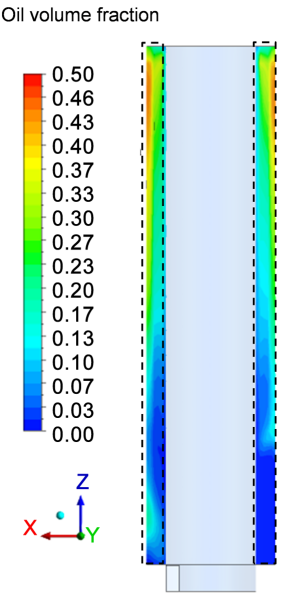

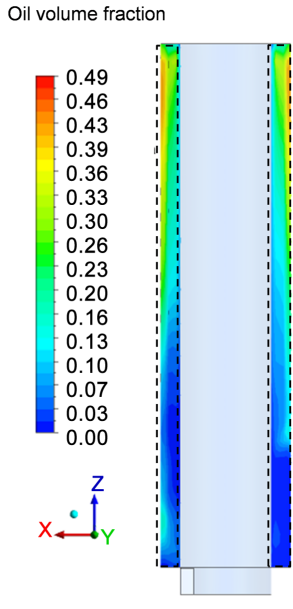

(c)

Figure 10. Oil fraction distribution inside the membrane, along the $\mathrm{x}$-axis $(\mathrm{Y}=0 \mathrm{~m})$ for feed velocity: (a) $35 \mathrm{~m} / \mathrm{s}$; (b) $40 \mathrm{~m} / \mathrm{s}$ and (c) $45 \mathrm{~m} / \mathrm{s}$.

despite the swirling zone observed in the initial section of the modules, the permeate flux occurred over the entire length of the module being more intense in 
the region close to the module's outlet.

\subsubsection{Performance of the Ceramic Membrane}

The membrane performance for water-oil separation was also analyzed for each case studied. The calculation of the separation efficiency was performed by the ratio between the oil mass flow rates at the concentrate outlet $\left(\dot{m}_{\text {outlet }}\right)$ and feed inlet $\left(\dot{m}_{\text {inlet }}\right)$, given as follows:

$$
\eta=\dot{m}_{\text {outlet }} / \dot{m}_{\text {inlet }}
$$

Table 4 and Table 5 present the extracted data of the simulations and the calculations of membrane separation efficiency for each case.

Upon analyzing these tables, it is clear the influence of both the membrane porosity and mixture feed velocity on the membrane module performance. Concerning porosity, it can be seen that the higher the membrane porosity, the greater the water-oil separation efficiency, due to less resistance to flow through the membrane. Unlike behavior was verified for the feed velocity. The higher the feed velocity, the higher the pressure gradient in the device and the higher resistance to oil passage, a complementary result to that observed in Figure 8 for the oil fraction distribution inside the membrane.

The maximum performance of $70 \%$ was verified for the operating condition: feed velocity of $40 \mathrm{~m} / \mathrm{s}$ and membrane porosity of 0.44 . This efficiency can be considered like moderate, and can be improved changing membrane permeability and membrane thickness, for example.

Table 4. Oil mass flow rates and separation efficiency of the device for different membrane porosity (feed velocity $40 \mathrm{~m} / \mathrm{s}$ ).

\begin{tabular}{llll}
\hline$\theta=0.35$ & $\dot{m}_{\text {inlet }}$ & $0.348 \mathrm{~kg} / \mathrm{s}$ & \\
& $\dot{m}_{\text {outlet }}$ & $0.209 \mathrm{~kg} / \mathrm{s}$ & \\
\hline$\theta=0.40$ & $\dot{m}_{\text {inlet }}$ & $0.347 \mathrm{~kg} / \mathrm{s}$ & \\
& $\dot{m}_{\text {outlet }}$ & $0.232 \mathrm{~kg} / \mathrm{s}$ & $\eta=66.8 \%$ \\
\hline$\theta=0.44$ & $\dot{m}_{\text {inlet }}$ & $0.347 \mathrm{~kg} / \mathrm{s}$ & $\eta=70.0 \%$ \\
\hline & $\dot{m}_{\text {outlet }}$ & $0.242 \mathrm{~kg} / \mathrm{s}$ & \\
\hline
\end{tabular}

Table 5. Oil mass flow rates and separation efficiency of the device for different mixture feed velocity (membrane porosity of 0.35 ).

\begin{tabular}{llll}
\hline & $\dot{m}_{\text {inlet }}$ & $0.304 \mathrm{~kg} / \mathrm{s}$ & \\
& $\dot{m}_{\text {outlet }}$ & $0.205 \mathrm{~kg} / \mathrm{s}$ & $\eta=67.0 \%$ \\
\hline$V=40 \mathrm{~m} / \mathrm{s}$ & $\dot{m}_{\text {inlet }}$ & $0.347 \mathrm{~kg} / \mathrm{s}$ & \\
& $\dot{m}_{\text {outlet }}$ & $0.209 \mathrm{~kg} / \mathrm{s}$ & \\
\hline & $\dot{m}_{\text {inlet }}$ & $0.391 \mathrm{~kg} / \mathrm{s}$ & \\
$V=45 \mathrm{~m} / \mathrm{s}$ & $\dot{m}_{\text {outlet }}$ & $0.219 \mathrm{~kg} / \mathrm{s}$ & $\eta=56.0 \%$ \\
\hline
\end{tabular}




\section{Conclusions}

This paper evaluated a fluid dynamic analysis and separation performance of a ceramic membrane module with tangential inlet of rectangular cross section used in oily water treatment. From the simulated results (Ansys CFX software) the following conclusions can be given: 1) The fluid mixture flow inside the separation module presented a strong three-dimensional behavior, mainly near the feed duct inlet; 2) The velocity profiles inside the membrane showed a significant similarity in all cases and recirculation zones immediately after the feed duct inlet; 3) The higher the membrane porosity the higher the oil volume fraction, the lower pressure inside the membrane, and the higher the separation efficiency of the device; 4) The higher the feed mixture velocity the lower the oil volume fraction inside the membrane, the higher the pressure gradient close to the inner membrane surface, and the lower the separation efficiency of the device; 5) An axisymmetric behavior of the pressure inside the module at each cross section was verified in all studied cases, and 6) The maximum separation efficiency of the module (70\%) was obtained when feed velocity of $40 \mathrm{~m} / \mathrm{s}$ and membrane porosity of 0.44 were applied.

\section{Acknowledgements}

The authors thank CNPq, CAPES and FINEP (Brazilian Research Agencies) for the financial support.

\section{Conflicts of Interest}

The authors declare no conflicts of interest in this paper.

\section{References}

[1] Moraes, J.E.F., Quina, F.H., Nascimento, C.A.O., Silva, D.N. and Chiavone Filho, O. (2004) Treatment of Saline Wastewater Contaminated with Hydrocarbons by the Photo-Fenton Process. Environmental Science \& Technology, 38, 1183-1187. https://doi.org/10.1021/es034217f

[2] Motta, A.R.P., Borges, C.P., Kiperstok, A., Esquerre, K.P., Araujo, P.M. and Branco, L. (2013) Produced Water Treatment for Oil Removal by Membrane Separation Process. Engenharia Sanitaria e Ambiental, 18, 15-26. (In Portuguese)

[3] Qiao, X., Zhang, Z., Yu, J. and Ye, X. (2008) Performance Characteristics of a Hybrid Membrane Pilot-Scale Plant for Oilfield-Produced Wastewater. Desalination, 225, 113-122. https://doi.org/10.1016/j.desal.2007.04.092

[4] Tibbetts, P.J.C., Buchanan, I.T., Gawel, L.J. and Large, R. (1992) A Comprehensive Determination of Produced Water Composition. In: Ray, J.P. and Engelhardt, F.R., Eds., Produced Water, Environmental Science Research, Vol. 46, Springer, Boston, 97-112. https://doi.org/10.1007/978-1-4615-2902-6_9

[5] Chakrabarty, B., Ghoshal, A.K. and Purkait, M.K. (2008) Ultrafiltration of Stable Oil-in-Water Emulsion by Polysulfone Membrane. Journal of Membrane Science, 325, 427-437. https://doi.org/10.1016/j.memsci.2008.08.007

[6] Souza, J.S., Paiva, M.K.N., Farias, F.P.M., Farias Neto, S.R. and Lima, A.G.B. (2010) Temperature Influence in the Process of Separating Water/Heavy Oil via Hydro- 
cyclone: Modeling and Simulation. XVIII Brazilian Chemical Engineering Congress, Foz do Iguaçu, Vol. 6, 2511-2520. (In Portuguese)

[7] Svarovsky, L. (2000) Solid-Liquid Separation. 2nd Edition, Elsevier, Londres.

[8] Thomas, J.E., Triggia, A.A., Correia, C.A., Verotto Filho, C., Xavier, J.A. and Machado, J.C.V. (2001) Petroleum Engineering Fundamentals. Editora Interciência, Petrobrás, Rio de Janeiro. (In Portuguese)

[9] Porciúncula, C.B. (2007) Computational Fluid Dynamics Simulation of Separation Processes by Membranes. Master's Dissertation in Chemical Engineering, Federal University of Rio Grande do Sul, Porto Alegre. (In Portuguese)

[10] Habert, A.C., Borges, C.P. and Nobrega, R. (2006) Separation Processes Membrane. Pilot School in Chemical Engineering, COPPE/UFRJ Chemical Engineering Program. (In Portuguese)

[11] Rader, A.S. (2003) Theoretical and Experimental Study of the Microfiltration Process of Silica Particles in Aqueous Suspension. Master's Dissertation in Chemical Engineering, Federal University of Rio Grande do Sul, Porto Alegre. (In Portuguese)

[12] Silva, F.A. (2009) Development of Tubular Ceramic Membranes from Regional Raw Materials for Microfiltration Process. Doctoral Thesis in Process Engineering, Federal University of Campina Grande, Campina Grande. (In Portuguese)

[13] Vieira, T.M., Souza, J.S., Barbosa, S.E., Cunha, A.L., Farias Neto, S.R. and Lima, A.G.B. (2012)Numerical Study of Oil/Water Separation by Ceramic Membranes in the Presence of Turbulent Flow. Advances in Chemical Engineering and Science, 2, 257-262. https://doi.org/10.4236/aces.2012.22030

[14] Souza, J.S. (2014) Theoretical Study of the Microfiltration Process in Ceramic Membranes. Doctoral Thesis in Process Engineering, Federal University of Campina Grande, Campina Grande. (In Portuguese)

[15] Cunha, A.L. (2014) Effluent Treatment of the Petroleum Industry via Membrane Ceramics-Modeling and Simulation. Doctoral Thesis in Chemical Engineering, UFCG, Campina Grande. (In Portuguese)

[16] Cunha, A.L., Souza, J.S., Farias Neto, S.R., Lima, A.G.B. and Barbosa, E.S. (2014) Separation Process by Porous Membranes: A Numerical Investigation. Advances in Mechanical Engineering, 6, 1-9. https://doi.org/10.1155/2014/469693

[17] Cunha, A.L., Farias Neto, S.R., Lima, A.G.B., Barbosa, E.S., Santos, J.P.L. and Silva, G.F. (2016) Water-Oil Separation Process Using a Concentric Tubular Ceramic Membrane Module: A Numerical Investigation. Brazilian Journal of Petroleum and Gas, 10, 205-219. https://doi.org/10.5419/bjpg2016-0017

[18] Magalhães, H.L.F., Barbosa de Lima, A.G., de Farias Neto, S.R., de Almeida, A.F., de Andrade, T.H.F. and Brandão, V.A.A. (2018) Ceramic Membranes: Theory and Engineering Applications. In: Delgado, J. and Barbosa de Lima, A., Eds., Transport Phenomena in Multiphase Systems, Advanced Structured Materials, Vol. 93, Springer, Cham, 111-137. https://doi.org/10.1007/978-3-319-91062-8_4

[19] Souza, J.S., Santos Filho, S.J., Farias Neto, S.R., Lima, A.G.B. and Magalhães, H.L.F. (2018) Mass Transfer in Tubular Ceramic Membranes for Polluted Water Treatment-Numerical Simulation. Diffusion Foundations, 20, 16-33. https://doi.org/10.4028/www.scientific.net/DF.20.16

[20] Magalhães, H.L.F., Moreira, G., Correia, B.R.B., Gomez, R.S., Lima, A.G.B. and Farias Neto, S.R. (2019) Thermo-Fluid Dynamics Analysis of the Oil-Water Separation Using Ceramic Membrane. Diffusion Foundations, 24, 37-60.

https://doi.org/10.4028/www.scientific.net/DF.24.37 
[21] Oliveira, J.P.S. (2019) Investigation with Computational Fluid Dynamics and Experimental Planning of Hydrocyclone for Separation of Water Dispersed in Oil. Doctoral Thesis, EPQB Federal University of Rio de Janeiro, Rio de Janeiro. (In Portuguese)

[22] Magalhães, H.L.F., Moreira, G., Gomez, R.S., Porto, T.R.N., Correia, B.R.B., Silva, A.M.V., Farias Neto, S.R. and Lima, A.G.B. (2020) Non-Isothermal Treatment of Oily Waters Using Ceramic Membrane: A Numerical Investigation. Energies, 13, 2092. https://doi.org/10.3390/en13082092 